\title{
Ldl-c Levels In Secondary Prevention: The Lower The Better and The Sooner The Better
}

\author{
Juan E Puche ${ }^{1}$, Diego Mialdea ${ }^{1}$ and Rafael Vázquez ${ }^{1,2 *}$ \\ ${ }^{1}$ Department of Cardiology, University Hospital Puerta del Mar, Cádiz, Spain \\ ${ }^{2}$ Institute of Biomedical Research and Innovation of Cádiz (INIBICA), Cádiz, Spain
}

Submission: May 10, 2021; Published: June 04, 2021

*Corresponding author: Rafael Vázquez, Department of Cardiology, University Hospital Puerta del Mar, Av. Ana de Viya, 21, 11009 Cádiz, Spain

Abstract

Ischemic heart disease continues to be the leading cause of death worldwide. Low-density lipoproteins cholesterol (LDL-c) is the main responsible factor in its pathophysiology. Despite the great farmacological advance in lipid-lowering treatments (estatins, ezetimibe, PCSK9 inhibitors and those that remain to come bempedoic acid and inclisiran) most of our patients in secondary prevention present LDL-c levels over the recommended by the Clinical Practice Guidelines. For this reason, we developed a specific program in an attempt to achieve the goal of lowering LDL-c the lower and the sooner the better.

Keywords: Low-density lipoproteins cholesterol; LDL-c; PCSK9 inhibitors; Acute coronary syndrome; Secondary prevention

Abbreviations: ACS, acute coronary syndrome; CPGs, Clinical Practice Guidelines; LDL-c, low-density lipoproteins cholesterol; PCSK9i, inhibitors of proprotein convertase subtilisin/kexin type 9

\section{Introduction}

The WHO reminds us that ischemic heart disease continues to be the leading cause of death worldwide. Over the last few years, a relevant scientific impulse has been developed aimed at investigating its pathophysiology, managing to identify different causes that, to a greater or lesser extent, are responsible for it. However, up to date, its main causal factor continues to be lowdensity lipoproteins cholesterol (LDL-c) [1-6].

For this reason, LDL-c reduction therapies are postulated as the best tool available for the secondary prevention of patients who have suffered an acute coronary syndrome (ACS). Since the initiation of statin therapy with lovastatin in 1987, great scientific evidence has been built on cholesterol-atheroma plaque causality in parallel with the therapeutic arsenal used, with the incorporation of ezetimibe [4,7] and inhibitors of proprotein convertase subtilisin/kexin type 9 (PCSK9i) [5,8], capable of reducing LDL-c levels to unusual values with previous therapies. In a few months we will have two new molecules: benpedoic acid [9], for patients intolerant to statins or as a complement in those patients bordering on the fulfillment of objectives and Inclisirán, a new drug based on RNA interference technology with promising results to change the routine of lipid-lowering treatment, with a biannual dosage [10].
Keeping in mind this impressive advance in cardiovascular prevention, it should be considered that clinical practice has already internalized that, when it comes to a reduction in LDL-C, "the lower the better". Consequently, it should have resulted in a higher success rate in achieving the lipid targets recommended by the Clinical Practice Guidelines (CPGs) based on the patient's risk score [11]. However, the latest multicenter secondary prevention studies such as EUROASPIRE [12] and DA VINCI [13] show poor lipid control in our patients despite the disponibility of drugs capable of achieving this goal. This is due to an inappropriate use of available treatments with an insufficient number of combination treatments (statins with ezetimibe) and a low use of PCSK9i.

In addition to the paradigm of "the lower the better", it is necessary to reduce LDL-c levels "the sooner the better". Obviously, this requires a closer follow-up of patients, with more frequent analytical controls and a greater dedication to meeting the lipid threshold, than is usually used in a conventional cardiology consultation. In this sense, in the Cardiology Service of the Puerta del Mar University Hospital, we have developed a specific program called "Post-ACS Virtual Consultation". It is aimed not only at achieving the LDL-c levels recommended by the CPGs [11] in the majority of patients in post-ACS secondary 
prevention, but also to accomplish it "the sooner the better". This idea emerged as an improvement action after analyzing our results from a previous series (2018). In this series, we achieved the goal of LDL-c $<70 \mathrm{mg} / \mathrm{dL}$ (still in force in 2018-2019) in 52\% of our post-ACS patients, after 1 year of follow-up [14]. Although these results improved those of the Euroaspire V study, they were insufficient, especially if we take into account the time elapsed until its achievement (almost 1 year) and that the new 2019 CPGs lowered the lipid target for LDL-c from 70 to $55 \mathrm{mg} / \mathrm{dL}$. Therefore, a more energetic and faster lipid control strategy was required than the one we had been using.

In 2020, we developed the "Post-ACS Virtual Consultation" and despite the COVID pandemic, we included more than 300 patients in this program. It basically consists of monthly monitoring and analytical control of patients who have suffered an ACS. These patients are discharged from hospital with high intensity statins, together with a request for a lipid profile within 1 month post ACS and are also included in a specific database. Analysis and telephone consultation are carried out every month. In these monthly telephone consultations, the treatment is escalated (increase in statins and/or ezetimibe and/or PCSK9i) until the lipid goal of LDL-c $<55 \mathrm{mg} / \mathrm{dL}$ is achieved. At this time, the "time until reaching the lipid goal" is computed, which is the main variable of this program.

We are currently finalizing the follow-up of the last patients included, but, in a preliminary way, we can anticipate that the vast majority of them achieved an LDL-c $<55 \mathrm{mg} / \mathrm{dL}$ and that the average time for this was around 3 months. Although this results are still preliminary, we believe that this more committed approach in the control of LDL-c will allow the achievement of the recommended objectives by the European CPG [11] in a greater percentage of patients and, especially, in a much shorter time than usual.

\section{Conclusion}

Given the known causal relationship between LDL-c and cardiovascular risk, a more conscientious strategy to reduce LDLc the lower and the sooner the better should help reduce the incidence of new ischemic hospitalizations after ACS.

Conflict of Interest: The authors declare no conflicts of interest.

Fundings: Project financed by the Ministry of Health of the Junta de Andalucía, through the project "PI-0057-2017" (from the Integrated Territorial Initiative -ITI-) and co-financed by Feder
Funds (European Regional Development Fund / European Social Fund).

\section{References}

1. Virchow R (1856) Gesammelte Adhandlunger zur Wissenschaftlichen Medicin Meidingir Sohn and Company, Frankfurt am main. page. 458.

2. (1994) Randomized trial of cholesterol lowering in 4444 patients with coronary heart disease: the Scandinavian Simvastatin Survival Study (4S). Lancet 344(8934): 1383-1389.

3. Cannon CP, Braunwald E, McCabe CH, Rader DJ, Rouleau JL, et al. (2004) Pravastatin or Atorvastatin Evaluation and Infection therapyThrombolysis in myocardial Infarction 22 Investigators. Intensive versus moderate lipid lowering with statins after acute coronary syndromes. N Engl J Med 350(15): 1495-1504.

4. Pradhan A, Bhandari M, Sethi R (2020) Ezetimibe and Improving Cardiovascular Outcomes: Current Evidence and Perspectives. Cardiol Res Pract 2020: 9815016.

5. Sabatine MS, Giugliano RP, Keech AC, Honarpour N, Wiviott SD, et al. (2017) Evolocumab and Clinical Outcomes in Patients with Cardiovascular Disease. Engl J Med 376(18): 1713-1722.

6. Wong ND, Toth PP, Amsterdam EA (2021) Most important advances in preventive cardiology during this past decade: Viewpoint from the American Society for Preventive Cardiology. American Society for Preventive Cardiology Trends Cardiovasc Med 31(1): 49-56.

7. Savarese G, De Ferrari GM, Rosano GM, Perrone-Filardi P (2015) Safety and efficacy of ezetimibe: A meta-analysis. Int J Cardiol 201: 247-252.

8. Schwartz GG, Steg PG, Szarek M, Bhatt DL, Bittner VA, et al. (2018) Alirocumab and Cardiovascular Outcomes after Acute Coronary Syndrome. ODYSSEY OUTCOMES Committees and Investigators. N Engl J Med 379(22): 2097-2107.

9. Ballantyne CM, Bays H, Catapano AL, Goldberg A, Ray KK, et al. (2021) Role of Bempedoic Acid in Clinical Practice. Cardiovasc Drugs Ther.

10. Ray KK, Scott Wright PR, Kallend D, Koenig W, Leiter LA, et al. (2020) Two Phase 3 Trials of Inclisiran in Patients with Elevated LDL Cholesterol. N Engl J Med 382(16): 1507-1519.

11. Mach F, Baigent C, Catapano AL, Koskinas KC, Casula M, et al. (2020) 2019 ESC/EAS Guidelines for the management of dyslipidaemias: lipid modification to reduce cardiovascular risk. European Heart Journal 41(1): 111-188.

12. Kotseva K, De Backer G, De Bacquer D, Rydén L, Hoes A, et al. (2019) Lifestyle and impact on cardiovascular risk factor control in coronary patients across 27 countries: Results from the European Society of Cardiology ESC-EORP EUROASPIRE V registry. Eur J Prev Cardiol 26(8): 824-835.

13. Ray KK, Molemans B, Schoonen WM, Giovas P, Bray S, et al. (2020) EUWide Cross-Sectional Observational Study of Lipid-Modifying Therapy Use in Secondary and Primary Care: the DA VINCI study. Eur J Prev Cardiol.

14. Delgado W, Puche JE, Villanueva D, Silva E, Vazquez R (2020) Lipidic control (LDLc) in patients after acute coronary syndromes: our experience in 2018. European Associantion of Preventive Cardiology Essentials 4 you. 
This work is licensed under Creative Commons Attribution 4.0 License DOI: 10.19080/JOCCT.2021.17.555954

\section{Your next submission with Juniper Publishers will reach you the below assets}

- Quality Editorial service

- Swift Peer Review

- Reprints availability

- E-prints Service

- Manuscript Podcast for convenient understanding

- Global attainment for your research

- Manuscript accessibility in different formats

( Pdf, E-pub, Full Text, Audio)

- Unceasing customer service

Track the below URL for one-step submission https://juniperpublishers.com/online-submission.php 